\title{
Scientific networks in the production of knowledge \\ in South Africa
}

AUTHOR:

Radhamany Sooryamoorthy ${ }^{\top}$

\author{
AFFILIATION: \\ 'Sociology Programme, School \\ of Social Sciences, University \\ of KwaZulu-Natal, Durban, \\ South Africa
}

CORRESPONDENCE TO:

Radhamany Sooryamoorthy

EMAIL:

sooryamoorthyr@ukzn.ac.za

POSTAL ADDRESS:

School of Social Sciences, MTB, Howard College Campus, University of KwaZulu-Natal, Durban 4041, South Africa

\section{KEYWORDS:}

productivity; professional activities; collaboration; networks; publication

\section{HOW TO CITE:}

Sooryamoorthy R. Scientific networks in the production of knowledge in South Africa. S Afr J Sci. 2016;112(5/6), Art \#a0155, 3 pages. http://dx.doi. org/10.17159/sajs.2016/a0155

(C) 2016. The Author(s). Published under a Creative Commons Attribution Licence.
It is now recognised that the systems of knowledge production have become a hybrid network system. ${ }^{1}$ This transition is an indication that professional contacts and networks are important in the production of scientific knowledge. Networking is indispensable in countries where scientific advancement is both a concern and a priority. Scientific networks are able to expand the horizons of knowledge sources and stimulate the exchange of ideas that lead to the creation of more new knowledge. ${ }^{2}$ Applied as a strategy in research, networking builds crucial professional contacts to improve the potential to produce knowledge. ${ }^{3}$ The scientific capital of a scientist tends to increase as the number of scientists with whom they connect increases. ${ }^{4}$

Professional networks turn out to be meaningful and beneficial to scientists in several ways. Firstly, professional contacts and networks assist scientists in forging new research alliances. These new research alliances eventually lead to the co-production of knowledge. Secondly, scientific networks are the building blocks in research which serve the function of disseminating information. ${ }^{5}$ Thirdly, networks improve the possibilities of expanding the capacities of knowledge production. ${ }^{6}$ Fourthly, networks can widen the circle of contacts, which leads to extensive participation in scientific matters, and to collaborative research enterprises. ${ }^{6}$

Literature on scientific networks enables us to conceptualise social structures as a set of ties and helps us to focus on the characteristics of the ties in the scientific system. ${ }^{7}$ Professional contacts are intentionally established by scientists, with a view to conduct, produce and publish new knowledge. The network of ties that is involved in scientific research influences not only the quantity but also the quality of production. It has been found that the greater the number of international ties of an author, the greater the likelihood that their work will be widely cited. ${ }^{8}$ Expected citation of a publication depends largely on the number of authors and the number of countries that participated in the production. ${ }^{8}$

Networks are often discussed in relation to collaboration. Collaboration consists of nodes (research units such as scientists, institutions and countries) and relational ties (collaborative relations). ${ }^{9}$ Despite the importance of networks in scientific research, the impact of the networks on the publication productivity of scientists has not been adequately investigated, ${ }^{10}$ more so in Africa.

This essay presents the findings of a series of empirical studies conducted in South Africa over the past 10 years. ${ }^{3,11-14}$ It focuses on scientific networks from the perspectives of collaboration and research productivity.

Scientists create and maintain networks to advance their research outcomes. Institutions often are positioned in the central and peripheral positions in co-authorship networks. ${ }^{9}$ Networks have been used as a proxy variable of collaboration in the study of South African scientists. ${ }^{15}$ The importance of social and professional networks in coauthorship has also been illustrated. ${ }^{16}$ In some cases, productivity, networks and research activities occur prior to the start of collaboration. ${ }^{17}$

Although there is a large reserve of empirical studies on scientific networks, theoretical models that explain them are rather inadequate. ${ }^{18}$ The network formation game is an exception. This model presents how network formation materialises as individuals make decisions in their scientific relationships through a link formation game. ${ }^{18}$ The decision of researchers to form a collaboration link with talented researchers is in line with a trade-off between rewards and costs involved in collaboration. The model is particularly useful in grasping the conditions under which researchers organise themselves into unequal and hierarchical scientific networks.

The formation of scientific networks is considered to be a strategy of academics ${ }^{19}$ that involves co-authoring and support networks. The number of strong professional ties in the support network is related to the quality of publications as well. ${ }^{19}$

\section{Relationship between scientific networks and scientific productivity}

There are several assumptions regarding the relationship between scientific productivity and networks. One is that scientific productivity is correlated with the existing networks that scholars maintain in their career. The results of the South African studies used in this essay support the hypothesis that the productivity of academics and scientists (i.e. the production of edited books, co-production of papers in national journals and co-authored books in particular) is positively associated with their scientific networks (total number of networks, total network locations, countrywide network, local networks, domestic networks and international networks) of all the respondents in the sample.

The relationship between scientific productivity and scientific networks varies between academics (in universities) and scientists (in research institutes). The results from the studies showed that the production of edited books was significantly related to the total network size and total network locations. A number of network variables (total networks, total network location, countrywide networks and domestic networks) were significant in their association with the co-production of papers in national journals. For scientists in research institutes, no association between any productivity or network variables was evident. The relationship between scientific productivity and scientific networks varied across the sample, i.e. academics and scientists. The connection between productivity and networks was not as prominent for scientists as for the academics in South Africa.

There is a view that professional activities of scholars are positively associated with their existing scientific networks; the data support this positive association with some key network variables. This relationship was not 
manifest in the case of scientists in research institutes, as much as it was significant for all scholars and academics in universities.

The study of South African academics and scientists has also uncovered the inter-relationships among scientific research, networks, professional activities and productivity. The South African scientific system holds characteristics that are revealed in the dimensions of professional activities, scientific networks and the production of knowledge. Scientific networks are essential for the professional activities and productivity of those who are engaged in scientific research. The scientific productivity and networks of the scholars, in many instances, were positively related. Measured under several indicators, the scientific productivity of scholars is seemingly relevant in influencing network variables. An increase in the size of the networks, particularly that of international links, is instrumental in the increase in this specific publication productivity. The relationship between the size of networks based in countries outside South Africa emphasises the international links the respondents maintain in their career. These links will also have positive effects on the professional activities of scholars. One additional dimension of this correlation between productivity and networks is co-publication.

Some of the co-publication productivity measures have connection with network measures. Evident also is the prominence of local and domestic networks in the co-publication outputs of the respondents. Scholars were found to maintain their networks with colleagues and peers, both in the region and within the country. In a way, this is the effect of the domestic collaboration that the respondents currently pursue in their professional life. The increased extent of contacts and networks, both within and outside the country, led to increased levels of productivity. Co-publications and networks are stronger than sole publications and networks.

Scholars are found to be different in their productivity and in the nature and size of scientific networks. For academics, the total network size and total network locations were crucial in the production of edited books. In the co-production of papers in national journals, the size of total networks, network locations, countrywide networks and domestic networks were applicable to academics, but not to scientists in research institutes. Co-production of papers in national journals brings in local collaboration. The increased size of the networks that were locally based (local, countrywide and domestic) had an influence on the co-production of publications in local journals. The contacts and networks academics built within their domestic surroundings have resulted in production that is local, but not international.

The above pattern in the production and co-production of research publications by academics is different from that of scientists in research institutes. None of the scientific network variables has shown any effect (or cause) on the productivity of scientists in research institutes. Networks seem to have no influence at all on the scientific productivity, individual or co-production, among scientists. This finding does not mean that scientists in research institutes do not produce at all. The contrast between academics and scientists in both the total productivity and coproductivity was very prominent. One explanation for this contrast is that scientists in research institutes are not expected to publish but only to conduct research. Publication is not a primary concern but research is. For academics, publications are crucial for their career advancement. In the current context in which publications are supported through government funding, universities encourage academics to be actively productive. There is an expectation at the national level that the academics, depending on their rank, produce a particular number of papers every year. The same expectation does not exist for scientists in research institutes in the country, whose core activity is limited to conducting research. This being the case, scientists are not keen to maintain their contacts for the purposes of producing publications in future. When there is a possibility or potential to conduct research together and to publish jointly then the contacts and networks become crucial and are therefore maintained. Normally, for scientists, their research itself is the end product. Other than personal motivation, there is no incentive for scientists to publish their research findings in a form other than reports. The research they conduct is either institution-based or inter-institutional but is ring-fenced within the country. Networks are therefore irrelevant for them in advancing their productivity or co-productivity.
Professional activities can lead to the creation (and maintenance) of networks. Attendance of seminars and conferences and the review of papers and books present opportunities to connect with peers. Most of the network variables in the studies reported here were positively associated with such professional activities. Network size, network location size, the size of the networks within the country, and international networks were connected to their professional activities. Professional activities are crucial to one's expanse of scientific networks, as scientific networks are also important in productivity. An explicit and straightforward relationship between many of the professional activities and networks among the respondents in general and academics in particular was discernible. In contrast, the same type of relationship did not exist for all the network variables among scientists in research institutes. Except in continental and international networks, professional activities are irrelevant for scientists. One reason for this trend among scientists versus academics is that the academics are more professionally active than scientists. They are more likely to avail themselves of professional opportunities as these are indispensable for their professional and career advancement. Academics participate in professional associations; organise and attend seminars, conferences and workshops; peer review for journals and publishers; and serve on committees. These activities put academics in an advantageous position to expand their connections with peers in their field, both nationally and internationally. Eventually these activities get translated into networks, contributing to their network contacts and productivity. Because of the nature of the work and the pressure of timebound research projects, scientists are more focused on their research than on professional activities. Spending time on work such as peer reviewing or other professional activities is therefore not in their career interests. They do, however, attend seminars and conferences, although not as frequently as their academic colleagues.

The results of the studies ${ }^{3,11-14}$ confirm the significance of variables that influence the scientific networks of academics and scientists. The size of the networks could be predicted on the basis of the professional activities. The size of the total network locations was also dependent on professional activities, namely, meetings. Also significant in the size of the networks was the amount of time they spent on research pursuits and total productivity. These findings contribute to the understanding of the productivity, professional activities and scientific networks of academics and scientists in South Africa.

There is a close association between professional activities, scientific networks and productivity. The amount of time scholars usually spend on research-related activities is reflected generally in the diversity of networks they have. The contrast in the networks between the two sets of respondents, academics and scientists, is obvious.

It is appropriate to compare the situation in South Africa to that reported by other studies elsewhere. In a study of US academics, it was observed that the frequency of the use of networks was obvious in the benefit of scholarly productivity. ${ }^{20}$ The greater the number of collaborators in a network, the greater the opportunity to access knowledge and skills. ${ }^{21}$ Correlation between production and collaboration - a proxy for networks - in a specific discipline has also been reported. ${ }^{6}$ Highly productive authors have higher than average rates of collaboration.

Studies that concur with the South African case showed that there is a positive and significant correlation between production and networks. ${ }^{22}$ A positive relationship between the output of authors and the centrality measures of authors is supported. ${ }^{22}$ Considering the network as a form of social capital, scientists employ a variety of networks configured in a way to enable their work. ${ }^{23}$ This has positive consequences for their productivity. In a university centre in the USA, professional linkages and network ties are instrumental in harnessing resources for productivity. ${ }^{24}$

The strong correlation between international research contacts and the publishing activity of scientists has also been established. ${ }^{25}$ It has also been demonstrated that networks through electronic means of communication increase productivity, and collaborations with strong ties are more productive. ${ }^{26}$ 
The above analysis on the scientific system of a developing country like South Africa, with its scientific edge over other African countries, offers some insight on the growth of scientific production. South Africa is a leading country in the production of scientific knowledge in subSaharan Africa. ${ }^{27}$ For South Africa to expand and consolidate its position in the production of scientific knowledge, due consideration of the factors identified is important. Measures to encourage professional activities, networking and collaboration can lead to a further increase in productivity of academics and scientists in the country.

The findings have significance beyond the borders of South Africa, particularly for other African countries. Building networks of contacts that eventually lead to collaborative research enterprises of scholars is to be viewed as a strategy for the production of knowledge. The linkage between collaboration and productivity further strengthens the need for professional contacts and networks in scientific research. This study of the South African research system once again reinforces the connection among networks, collaboration and production of knowledge.

\section{Acknowledgement}

Funding received from the National Research Foundation (South Africa) to conduct the studies reported in this essay is gratefully acknowledged.

\section{References}

1. Heimeriks G, Horlesberger M, Besselaar PVD. Mapping communication and collaboration in heterogeneous research networks. Scientometrics. 2003;58(2):391-413. http://dx.doi.org/10.1023/A:1026296812830

2. Lee DH, Seo IW, Choe HC, Kim HD. Collaboration, network patterns and research performance: The case of Korean public research institutions. Scientometrics. 2012;91:925-942. http://dx.doi.org/10.1007/s11192-0110602-8

3. Sooryamoorthy R. Internet technology and the epistemic strategies of scientists in post-apartheid South Africa: Race as a decisive factor. Tec Soc. 2015;40:73-81. http://dx.doi.org/10.1016/j.techsoc.2014.08.003

4. Jonkers K, Tijssen R. Chinese researchers returning home: Impacts of international mobility on research collaboration and scientific productivity. Scientometrics. 2008;77(2):309-333. http://dx.doi.org/10.1007/s11192007-1971-x

5. Corley EA, Boardman PC, Bozeman B. Design and the management of multi-institutional research collaborations: Theoretical implications from two case studies. Res Pol. 2006;35(7):975-993. http://dx.doi.org/10.1016/j. respol.2006.05.003

6. De Granda-Orive Jl, Villanueva-Serrano S, Aleixandre-Benavent R, Valderrama-Zurián JC, Alonso-Arroyo A, García Rio F, et al. World-wide collaboration among medical specialties in smoking research: Production, collaboration, visibility and influence. Res Eval. 2009;18(1):3-12. http:// dx.doi.org/10.3152/095820209X393163

7. Otte E, Rousseau R. Social network analysis: A powerful strategy, also for the information sciences. J Inf Sci. 2002;28(6):441-453. http://dx.doi. org/10.1177/016555150202800601

8. Goldfinch S, Dale T, DeRouen K Jr. Science from the periphery: Collaboration, networks and 'periphery effects' in the citation of New Zealand Crown Research Institutes articles, 1995-2000. Scientometrics. 2003;37(3):321337. http://dx.doi.org/10.1023/A:1025048516769

9. Chang $\mathrm{H}-\mathrm{W}$, Huang $\mathrm{M}-\mathrm{H}$. Prominent institutions in international collaboration network in astronomy and astrophysics. Scientometrics. 2013;97:443-460. http://dx.doi.org/10.1007/s11192-013-0976-x
10. Ynalvez M, Shrum W. Professional networks, scientific collaboration, and publication productivity in resource-constrained research institutions in a developing country. Res Pol. 2011;40:204-216. http://dx.doi.org/10.1016/j. respol.2010.10.004

11. Sooryamoorthy R, Shrum W. Does the internet promote collaboration and productivity? Evidence from the scientific community in South Africa. J Comput Mediat Commun. 2007;12(2):733-751. http://dx.doi.org/10.1111/ j.1083-6101.2007.00347.x

12. Sooryamoorthy R. Publication productivity and collaboration of researchers in South Africa: New empirical evidence. Scientometrics. 2014;98:531-545. http://dx.doi.org/10.1007/s11192-013-0990-z

13. Sooryamoorthy R. Transforming science in South Africa: Development, collaboration and productivity. Basingstoke and New York: Palgrave Macmillan; 2015. http://dx.doi.org/10.1057/9781137493071

14. Sooryamoorthy R. Producing information: communication and collaboration in the South African scientific community. Inf Commun Soc. 2016;12(2):141159. http://dx.doi.org/10.1080/1369118X.2015.1047392

15. Durbach IN, Naidoo D, Mouton J. Co-authorship networks in South African chemistry and mathematics. S Afr J Sci. 2008;104:487-492. http://dx.doi. org/10.1590/S0038-23532008000600024

16. Newman MEJ. Coauthorship networks and patterns of scientific collaboration Proc Natl Acad Sci USA. 2004;101(suppl.1):5200-5205. http://dx.doi. org/10.1073/pnas.0307545100

17. Yoshikane F, Nozawa T, Shibul S, Suzuki T. An analysis of the connection between researchers' productivity and their co-authors' past attributions, including the importance in collaboration networks. Scientometrics. 2009;79(2):435-449. http://dx.doi.org/10.1007/s11192-008-0429-8

18. Rubí-Barceló A. Core/periphery scientific collaboration networks among very similar researchers. Theo Dec. 2012;72:463-483. http://dx.doi.org/10.1007/ s11238-011-9252-9

19. Sebestyén T, Varga A. Research productivity and the quality of interregional knowledge networks. Ann Reg Sci. 2013;51(1):155-189. http://dx.doi. org/10.1007/s00168-012-0545-x

20. Cohen J. Computer mediated communication and publication productivity among faculty. Int Res. 1996;6(2/3):41-63. http://dx.doi. org/10.1108/10662249610127328

21. Defazio D, Lockett A, Wright M. Funding incentives, collaborative dynamics and scientific productivity: Evidence from the EU framework program. Res Pol. 2009;38(2):293-305. http://dx.doi.org/10.1016/j.respol.2008.11.008

22. Hou H, Kretschmer H, Liu Z. The structure of scientific collaboration networks in scientometrics. Scientometrics. 2006;75(2):189-202. http://dx.doi. org/10.1007/s11192-007-1771-3

23. Bozeman B, Dietz J, Gaughan M. Scientific and technical human capital: An alternative model for research evaluation. Int J Technol Manage. 2001;22(78):636-655. http://dx.doi.org/10.1504/IJTM.2001.002988

24. Ponomariova BL, Boardman PC. Influencing scientists' collaboration and productivity patterns through new institutions: University research centers and scientific and technical human capital. Res Pol. 2010;39(5):613-624. http://dx.doi.org/10.1016/j.respol.2010.02.013

25. Kyvik S, Larsen M. International contact and research performance. Scientometrics. 1994;29(1):161-172. http://dx.doi.org/10.1007/BF02018388

26. Walsh JP, Maloney NG. Computer network use, collaboration structures and productivity. In: Hinds P, Kiesler S, editors. Distributed work. Cambridge, MA: MIT Press; 2002. p. 433-458.

27. Pouris A. Science in South Africa: The dawn of a renaissance? S Afr J Sci. 2012;108(7/8), Art. \#1018, 6 pages. http://dx.doi.org/10.4102/sajs. v108i7/8.1018 